of termites. We know surprisingly little concerning the nutritional requirements of blood-sucking insects which are concerned with the transmission of the pathogenic agents of certain virulent diseases. We need to know the length of time such insects can exist in the absence of a blood meal, the extent to which digestion of blood requires the interaction of microorganisms, the influence of different types of blood upon fecundity, and the extent to which the selection of one mammalian host in preference to another is a chemical or a biological problem.

These few comments will serve to indicate the nature and importance of some of the problems involved. It is to the credit of the Dietetics Subcommittee of the Civil Research Committee that it directed attention to the need for examination of the nutritional problem in insects. Through the Empire Marketing Board it was able to arrange with the Imperial Bureau of Entomology to produce a collated bibliography of the whole subject, and Mr. Uvarov's memoir was the result. On the submission of the MS. to the Civil
Research Subcommittee, the latter body approached the council of the Entomological Society of London, through the Empire Marketing Board, with a view to its publication. It must be added that the financial provision was made by the Empire Marketing Board, and that it affords yet another example of the breadth of view and wise foresight exercised by that Board in the furtherance of applied biological research.

The inception, preparation, and publication of this memoir reflects the greatest credit on all concerned. It may be added that Mr. Uvarov's actual summaries of the papers listed in his bibliography have been deposited in the Reid Library of the Rowett Research Institute for Animal Nutrition, Aberdeen. Arrangements have also been made for a set to be placed in the Science Library at South Kensing. ton, where they will likewise be available for consultation. A limited number of copies of $\mathrm{Mr}$. Uvarov's memoir are available on application to the Secretary, Committee of Civil Research, 2 Whitehall Gardens, S.W.1.

\title{
Annual Visitation of the Royal Observatory, Greenwich.
}

$A \mathrm{~T}$ the annual visitation of the Royal Observatory, A Greenwich, by the Board of Visitors on Saturday, June 1, the Astronomer Royal presented his report, which describes the work of the observatory during the year ended on May 10. The observations with the transit circle numbered nearly nine thousand, embracing the sun, moon, planets (of which special attention was paid to Vesta, owing to its value for determining the equator point), fundamental stars, and stars needed for comparison with Eros at the time of its near approach to the earth in 1930-31. The correction to the longitude of the moon as calculated from Brown's tables is $+\mathbf{5 \cdot 5 l ^ { \prime \prime }}$ from the limb and $+5 \cdot 83^{\prime \prime}$ from the crater Mosting $\mathrm{A}$. The correction has been diminishing at the rate of a third of a second per annum since Brown's tables were introduced into the almanacs in 1923. The early observa. tions of the sun and moon, from 1751 onwards, have been re-reduced; it is found that the longitudes deduced from the declinations are more trustworthy in the early years than those from the right ascensions. The results give support to the theory that there are variations in the earth's rate of rotation; they also indicate a secular acceleration of the sun's longitude, the amount of which is $+0.78^{\prime \prime}$ in a century.

Observations with the Cookson Zenith Telescope show that the variation of latitude in recent years has been abnormally small ; the large amplitude of seven years earlier has not been repeated.

The 28-inch equatorial has been used for double star observation; 282 stars have been measured during the year, 44 of which are separated by less than half a second; a new working list of some 2000 pairs discovered by Dr. Aitken has been prepared. The old water-clock used for driving this instrument, and its predecessor the Merz equatorial, since Airy's days has been superseded by an electric drive of the Gerrish type, which was on view for the first time at the visitation. The Astronomer Roval gratefully acknowledges the help given in preparing the plans by Mr. F. J. Hargreaves, who had used a similar drive successfully on his small equatorial at Kingswood, Surrey. It was with this instrument that he was the first to photograph the comet Crigg-Skjellerup at its return in 1927.

Thirty-one stellar parallaxes were determined with the Thompson 26-inch equatorial during the year, bringing the total up to date to 400 . A useful economy has been introduced of taking two parallax fields on the same plate; this halves the time spent in development.

The 30 -inch reflector is being used for the determination of ' colour temperature' of stars. The absolute temperatures are obtained by comparison with the positive crater of a carbon arc lamp, which is mounted on the roof of the octagon room, 600 feet away. Twenty-four early-type stars, distributed as uniformly as possible round the northern hemisphere, have been selected as standards; forty other stars have now been compared with these; the comparisons being made at the same altitude in each case. Some notes on B-type stars of abnormally low temperature were published in the Monthly Notices last year.

With the astrographic equatorial, plates are being taken for comparison with those taken twenty-five to thirty years ago, in order to determine proper motions The result of this study for the zones from Decl. $+64^{\circ}$ to $+72^{\circ}$ is now in the press. The sunspot curve gives indications of a double peak, in 1926 and 1928 respectively. Daily spot numbers, both of the whole disc and of the central region, are sent to Zurich for the Bulletin which is published there under the auspices of the International Astronomical Union.

The magnetic elements determined at Abinger for the year 1928 are : Decl. $12^{\circ} 47 \cdot 0^{\prime} \mathrm{W}$.; Hor. Force, $0 \cdot 18564$; Vert. Force, $0 \cdot 42941$; Dip, $66^{\circ} 37 \cdot 3^{\prime}$; the Decl. is diminishing about $12^{\prime}$ por annum.

The mean temperature of the year ending on April 30,1929 (misprinted 1928 in the report), was $48^{\circ} \cdot 7$, or $0^{\circ} .8$ below the average. Frost occurred on 71 days; the rainfall was $20 \cdot 46$ inches, or 3.78 below the average. March, with 0.038 inch, was the driest month ever recorded at Greenwich.

The performance of the two Shortt sidereal clocks has been very satisfactory; the temperature in the clock cellar is now maintained at $62^{\circ} .8 \mathrm{Fahr}$. The progressive increase of losing rate still continues; it is proposed to substitute a bob of invar on one of the clocks.

Daily comparisons of time are made with Paris, Nauen, Annapolis, and Bordeaux. In all four cases the residuals appear to show an annual wave.

Allusion is made to the eclipse expedition to Kedah and Siam. The total equipment weighed ten tons. Unfortunately, no results were obtained in the investigation of the Einstein bending of light; but some results on the corona and prominences were obtained at Alor Star.
A. C. D. Crommeisin.

No. 3110 , VoL. 123] 